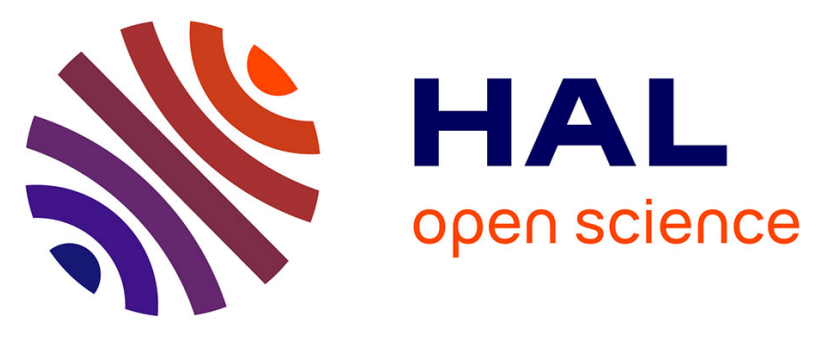

\title{
Deciphering the Chemistry of Cultural Heritage: Targeting Material Properties by Coupling Spectral Imaging with Image Analysis
}

Loïc Bertrand, Mathieu Thoury, Pierre Gueriau, Étienne Anheim, Serge X. Cohen

\section{To cite this version:}

Loïc Bertrand, Mathieu Thoury, Pierre Gueriau, Étienne Anheim, Serge X. Cohen. Deciphering the Chemistry of Cultural Heritage: Targeting Material Properties by Coupling Spectral Imaging with Image Analysis. Accounts of Chemical Research, 2021, 54 (13), pp.2823-2832. 10.1021/acs.accounts.1c00063 . hal-03329879

\section{HAL Id: hal-03329879 \\ https://hal.science/hal-03329879}

Submitted on 12 Sep 2021

HAL is a multi-disciplinary open access archive for the deposit and dissemination of scientific research documents, whether they are published or not. The documents may come from teaching and research institutions in France or abroad, or from public or private research centers.
L'archive ouverte pluridisciplinaire HAL, est destinée au dépôt et à la diffusion de documents scientifiques de niveau recherche, publiés ou non, émanant des établissements d'enseignement et de recherche français ou étrangers, des laboratoires publics ou privés. 


\title{
Deciphering the Chemistry of Cultural Heritage: Targeting Material Properties by Coupling Spectral Imaging with Image Analysis
}

\author{
Loïc Bertrand,* Mathieu Thoury, Pierre Gueriau, Étienne Anheim, and Serge Cohen*
}

Cite This: https://doi.org/10.1021/acs.accounts.1c00063

Read Online

\section{ACCESS |}

Џll Metrics \& More

回 Article Recommendations

CONSPECTUS: The chemical study of materials from natural history and cultural heritage, which provide information for art history, archeology, or paleontology, presents a series of specific challenges. The complexity of these ancient and historical materials, which are chemically heterogeneous, the product of alteration processes, and inherently not reproducible, is a major obstacle to a thorough understanding of their making and long-term behavior (e.g., fossilization). These challenges required the development of methodologies and instruments coupling imaging and data processing approaches that are optimized for the specific properties of the materials. This Account discusses how these characteristics not only constrain their study but also open up specific innovative avenues for providing key historical information. Synchrotron methods have extensively been used since the late 1990s to study heritage objects, in particular for their potential to provide speciation information from excitation spectroscopies and to image complex heritage objects and samples in two and three dimensions at high resolution. We examine in practice how the identification of key intrinsic chemical specificities has offered fertile ground for the development of novel synchrotron approaches allowing a better stochastic description of the properties of ancient and historical materials. These developments encompass three main aspects: (1) The multiscale heterogeneity of these materials can provide an essential source of information in the development of probes targeting their multiple scales of homogeneity. (2) Chemical alteration can be described in many ways, e.g., by segmenting datasets in a semiquantitative way to jointly inform morphological and chemical transformation pathways. (3) The intrinsic individuality of chemical signatures in artifacts triggers the development of specific strategies, such as those focusing on weak signal detection. We propose a rereading of the advent of these new methodologies for analysis and characterization and examine how they have led to innovative strategies combining materials science, instrument development, history, and data science. In particular, we show that spectral imaging and the search for correlations in image datasets have provided a powerful way to address what archeologists have called the uncertainty and ambiguity of the material record. This approach has implications beyond synchrotron techniques and extends in particular to a series of rapidly developing approaches that couple spectral and spatial information, as in hyperspectral imaging and spatially resolved mass spectrometry. The preeminence of correlations holds promise for the future development of machine learning methods for processing data on historical objects. Beyond heritage, these developments are an original source of inspiration for the study of materials in many related fields, such as environmental, geochemical, or life sciences, which deal with systems whose alteration and heterogeneity cannot be neglected.

\section{KEY REFERENCES}

- Thoury, M.; Mille, B.; Séverin-Fabiani, T.; Robbiola, L.; Réfrégiers, M.; Jarrige, J.-F.; Bertrand, L. High spatial dynamics-photoluminescence imaging reveals the metallurgy of the earliest lost wax-cast object. Nat. Commun. 2016, 7, 13356. ${ }^{1}$ High-definition photoluminescence imaging was developed to characterize semiconductor defects in the corrosion of the oldest evidence of an investment casting and reconstruct the artifact's manufacturing process.

- Georgiou, R.; Gueriau, P.; Sahle, C.; Bernard, S.; Mirone, A.; Garrouste, R.; Bergmann, U.; Rueff, J.-P.; Bertrand, L. Carbon speciation in organic fossils using
$2 \mathrm{D}$ to 3D X-ray Raman multispectral imaging. Sci. Adv. 2019, 5, eaaw5019. ${ }^{2}$ Direct tomography based on X-ray Raman spectroscopy enabled visualization of the differential alteration in the cuticle of a 53-million-year-old fossil ant.

Received: January 27, 2021 
- Reynaud, C.; Thoury, M.; Dazzi, A.; Latour, G.; Scheel, M.; Li, J.; Thomas, A.; Moulherat, C.; Didier, A.; Bertrand, L. In-place molecular preservation of cellulose in 5,000-year-old archeological textiles. Proc. Natl. Acad. Sci. U.S.A. 2020, 117, 19670-19676. ${ }^{3}$ Nanoresolution imaging methods were coupled to describe the processes leading to the exceptional preservation of cellulosic textiles from the Middle East in a mineralized state.

- Maldanis, L.; Hickman-Lewis, K.; Verezhak, M.; Gueriau, P.; Guizar-Sicairos, M.; Jaqueto, P.; Trindade, R.; Rossi, A. L.; Berenguer, F.; Westall, F.; Bertrand, L.; Galante, D. Nanoscale 3D quantitative imaging of 1.88 Ga Gunflint microfossils reveals novel insights into taphonomic and biogenic characters. Sci. Rep. 2020, 10, 8163. Microfossils were described using coherent diffraction imaging techniques and semiquantitative determination of phase densities.

\section{INTRODUCTION}

Ancient materials provide unique information about the past. Painting or metallurgical techniques can be accurately described, as can the chemical degradation mechanisms affecting works of art. The sequence of operations used in the manufacture of archeological objects can be studied. Paleontological specimens from natural history collections can be described in terms of morphology, evolution, and development. Corresponding material systems are mainly studied within the framework of highly interdisciplinary projects that bring together the fields required for their study and tackle the history, the "biography" or "social life" of individual objects, series, or collections. However, just as the natural sciences often exclude historical accidents from their models, the social sciences mostly consider the social life of objects to the exclusion of their physicochemical evolution in general, in an approach very focused on uses rather than on impact on material structure, composition, etc. The use of classical methods of chemical analysis is confronted with the constraints posed by the compositional complexity of these material systems. ${ }^{5-8}$ Many works have therefore requested the development of specific methodologies or instruments that integrate such constraints directly into experimental frameworks.

A specific illustration is the emergence of photonic approaches dedicated to ancient materials at synchrotrons. Since the seminal articles of Brissaud et al. ${ }^{9}$ and Harbottle et al., ${ }^{10}$ synchrotron-based methods have led to a wealth of new information on ancient materials. ${ }^{7,11-19}$ Ancient materials studies took particular benefit of the extreme brightness, tunability, and transverse coherence of synchrotron sources. ${ }^{16}$ These developments included the following in particular: (a) New generations of rapid X-ray fluorescence (XRF) scanners were used to produce elemental distribution maps of artworks combining information on local pigment identities and pictorial composition. ${ }^{20,21}$ Similar approaches were used to image the composition of hard and soft tissues in flat fossil specimens from natural history collections and to study the chemistry of their fossilization. ${ }^{22-26}$ (b) X-ray absorption spectroscopy (XAS) has been used to study many heritage materials, in particular paints, glasses, and ceramics. ${ }^{27}$ Soft XAS has provided chemical speciation of light elements such as carbon, nitrogen, and oxygen and of heavier elements through the study of their $\mathrm{L}$ absorption edges, opening up the possibility of nanoresolved speciation and identification of organic molecules in heritage systems. ${ }^{28-30}$ Recent developments in X-ray Raman spectroscopy have extended the scope of X-ray absorption near-edge spectroscopy (XANES) for light elements to bulk spectroscopy and three-dimensional (3D) imaging. $^{2,31}$ (c) X-ray microtomography $(\mu \mathrm{CT})$ enabled $3 \mathrm{D}$ internal morphological rendering of many heritage objects based on contrasts in their internal density and, more generally, their complex optical index. Edge enhancement by beam propagation after traversing the analyzed object or phase reconstruction, both of which result from the very small photon source of third-generation synchrotrons, have greatly facilitated segmentation and morphological recognition, particularly for paleontological specimens. ${ }^{32-36}$ The advent of coherence-based tomography made it possible to couple imaging and phase identification in three dimensions with nanometric resolution. ${ }^{4}$ (d) Infrared spectroscopy has enabled high signal-to-noise microscale characterization of organic and in some cases inorganic systems and has been used extensively for the study of archeological and historical paint samples. ${ }^{37,38}$ (e) By giving access in particular to the deep UV, UV/vis photoluminescence (PL) spectroscopy of ancient materials on synchrotron has opened new avenues for the study of semiconductor compounds and paint alteration phases at the micrometer and submicrometer scales. ${ }^{1,39,40}$

Despite their great diversity, insofar as they are studied from a historical perspective, the constituent materials of art objects, monuments, archeological artifacts, and natural history specimens (human-made or not, artifacts and ecofacts) share a set of common characteristics. These intrinsic characteristics distinguish them from other materials and strongly condition their characterization from sample preparation and analysis to data processing. ${ }^{6}$ In this Account, we detail how the experimental logic can be reversed: through the identification of these main physicochemical specificities, inspiring constraints could be identified and used to develop new classes of methodologies or instruments toward augmented knowledge about heritage objects and their contexts (Figure 1).

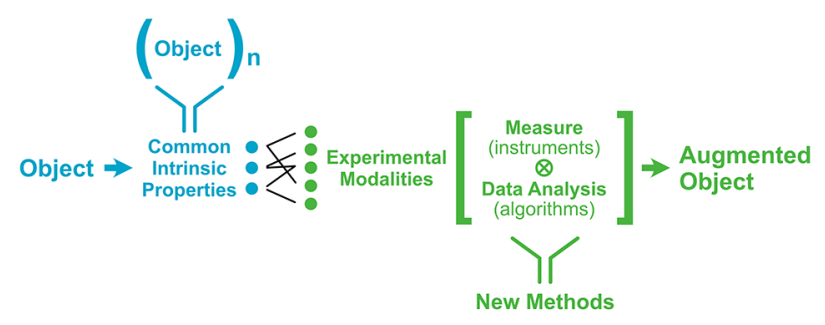

Figure 1. Schematic representation showing how the common intrinsic properties of heritage materials are linked with the experimental modalities of measurement and data analysis, as discussed in this Account.

\section{HETEROGENEITY AND MULTISCALE REGULARITY}

\section{Common Intrinsic Properties}

Ancient objects are highly heterogeneous because of their original chemistry and the transformation they underwent, whether intentional or not. In this Account, the word "composition" is used in its broadest sense, encompassing structure, chemical environment, crystalline defects, molecular structure, etc. Similarly, by "object" we refer to what is observed without implying a distinction between the sample and its 
surroundings. This is important because many research works in the field focus precisely on the interface between an artifact or specimen and its milieu. For example, the cross sections required to study a corroded archeological artifact will generally include the first layers of the transformed soil. Heritage objects are generally made up of various materials, often both organic and inorganic, that the classes of analytical techniques probe in a nonbijective way. These assemblages can be particularly complex, ${ }^{41}$ and their physicochemical heterogeneity can extend over several orders of magnitude in length-for example, from decimeters to nanometers for a paint stratigraphy on a canvas. This spatial organization is not random: their frequently encountered inclusionary, textured, stratified, or interfacial features are of a complexity imported from the original materials, human intervention, and alteration. For example, brush strokes or canvas structures are tangible proxies of an artistic practice. ${ }^{42}$ These aspects are related to source materials, formation processes, and artistic gestures as well as to fluid transport and percolation, microenvironment, and alteration processes, making them in turn signatures of these processes. This first set of common intrinsic properties can be structured into main points:

- Piecewise smoothness: this is typical of the 3D multiphasic/polycrystalline spatial architecture of ancient systems, which often show a piecewise regularity.

- Sparsity: materials contain a limited number of main "pure" constituents.

- Multiscale texture: ${ }^{43}$ motifs are repeated with certain patterns that define homogeneity length scales.

- Local perturbations: minor deviations can be studied as perturbations from pure compositions, adding some diversity in the parsimonious view generated by the above criteria. For example, diffusion of fluids can lead to the deposition of chemical elements in low concentrations in an otherwise chemically homogeneous matrix.

\section{Experimental Modalities}

Bertrand et al. ${ }^{7}$ and Anheim et al. ${ }^{6}$ have postulated that heterogeneity in its plurality of meanings is a critical parameter in the design of new methods and have discussed the development of instruments addressing the three levels of spectral, spatial, and signal dynamics. Trentelman ${ }^{8}$ has discussed the impact of the "heterogeneous hierarchy" on the imaging of cultural heritage artifacts. The coupling between the spectral and spatial acquisition modalities, facilitated by the specific characteristics of the synchrotron source, makes it possible to address the three types of dynamics (in particular high spatial dynamics thanks to high-definition spectral imaging). ${ }^{7}$ It is then possible to describe multidimensional shapes in the (spectral, spatial) space by adopting appropriate data processing modalities.

Two main routes are used to process images: factorization for mixed sparsity, where data in individual pixels are considered as coming from mixtures of multiple components (factors), and classification (or segmentation) for unmixed sparsity, where data in pixels are considered as pure components. For spectral images, a three-step process is often used: (i) data are reduced through factorization of the spectral image (called supervised factorization for known factors, and unsupervised factorization for unknown factors); (ii) classification is then based on the activity images (spatial representation); and (iii) spectral data from pixels in each class are aggregated (e.g., averaged) to compute a representative spectrum of each class. A typical example is the decomposition of spectral images based on major-to-trace elemental maps, as illustrated by the XRF imaging of $\mathrm{Pb}$ that showed the presence of lead soaps formed during the alteration of a Piet Mondrian artwork (Figure 2). The presence of thallium, which was
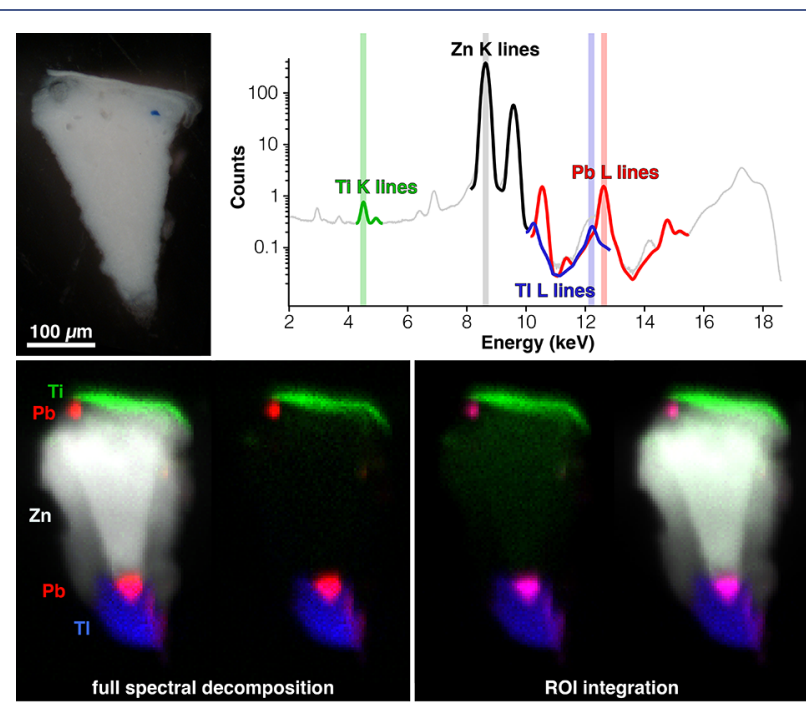

Figure 2. Synchrotron XRF mapping of a cross-section sample of zinc white paint from a composition by Piet Mondrian (1872-1944). Although they are not visible or hardly visible in dark-field microscopy (top left), elemental distributions distinguish (from top to bottom) a thin $20 \mu \mathrm{m}$ layer rich in titanium covering the zinc white paint and a $100 \mu \mathrm{m}$ layer rich in thallium as well as several large lead soap aggregates with diameters of $20-50 \mu \mathrm{m}$. Since the $\mathrm{Pb}$ and $\mathrm{Tl} \mathrm{L}$ lines are in the same energy domain, a full spectral decomposition of the data is required to properly separate their respective contributions, which otherwise overlap and lead to (artifactual) pink domains in the false-color image produced simply by integrating the signal in energy regions of interest.

undoubtedly identified using spectral fitting, was totally unexpected. Its distribution, obtained by a complete spectral decomposition of the data, confines it to an almost transparent area in optical photography in which the pigment used remains unknown.

A second example is the sparse-excitation XAS spectral factorization procedure conducted from a known base of reference spectra introduced by Cohen et al. ${ }^{44}$ to rapidly map the distribution of chemical speciation across heterogeneous samples. In the example presented in Figure 3, Gueriau et al. ${ }^{45}$ used this approach to map the two oxidation states of the rareearth element cerium (Ce(III) and $\mathrm{Ce}(\mathrm{IV}))$ in the cuticle and gills of an $\sim 100 \mathrm{Ma}$ fossil crab from Morocco. While the concentration of Ce varied greatly between the two tissues, the $[\mathrm{Ce}(\mathrm{III})$ or $\mathrm{Ce}(\mathrm{IV})] /[\mathrm{Ce}($ tot $)]$ ratios were found to be very homogeneous, indicating similar incorporation, which took place for thousands of years after death.

In their study of mineralized textile fibers, such as those from an archeological flax textile remnant from the Gonur-Depe site, Reynaud et al. ${ }^{3}$ studied the (single-channel) signal of a virtual $\mu \mathrm{CT}$ volume from a collinear dictionary. They segmented the dataset by identifying pixels belonging to discrete grayscale ranges to map the distribution of the phases present, working at the limit of the discrimination of attenuation in white-beam $\mu \mathrm{CT}$. This distribution was crucial to identify the molecular 

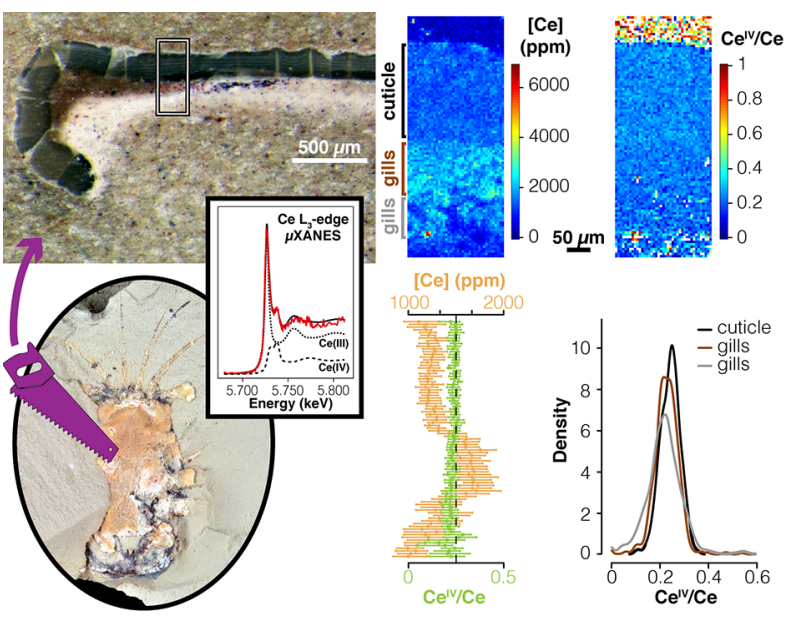

Figure 3. Synchrotron XAS mapping of the two oxidation states of cerium in the cuticle and gills of a newly discovered specimen of crab from the Jbel oum Tkout Lagerstätte ( $\sim 100 \mathrm{Ma}$, Morocco). The top and bottom middle panels display the image and profile of the mean total Ce content (in ppm), respectively, and the top and bottom right panels show the image and profile of the $[\mathrm{Ce}(\mathrm{IV})] /[\mathrm{Ce}(\mathrm{tot})]$ ratio, respectively, along a cross-section through the carapace of the fossil (left). Scan step $5 \mu \mathrm{m} \times 5 \mu \mathrm{m}, 4141$ pixels.

mechanisms involved at different time scales in the nanoscale taphonomy of these cellulosic remains and to show in particular the complex interplay between the three stages of protection, controlled alteration, and silicification (Figure 4).

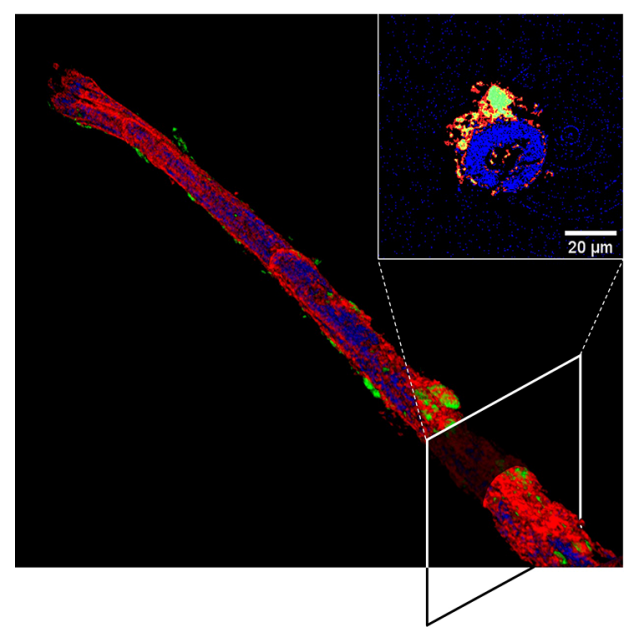

Figure 4. Microtomography coupled with semiquantitative decomposition of the attenuation histogram showed the distribution of the phases formed during the exceptional mineralization of a 5000-yearold mineralized fiber from the archeological site of Gonur-Depe (Turkmenistan) by synchrotron-based X-ray microtomography. The false-color image shows that the fiber has preserved an organic character (blue) and has on its surface copper silicates (green), which played a major role in its preservation, and soil compounds (red).

In spectral image classification, one of the difficulties lies in choosing the number of classes to consider, and one possible approach is illustrated by the study of FT-IR spectra of historical musical instrument materials, which used a penalized jump heuristic to determine the optimal number of classes in terms of completeness of information. ${ }^{46}$ Two important prerequisites must be addressed for all of the above approaches: the data need to be properly calibrated using appropriate metrology (see, e.g., Bertrand et $\mathrm{al}^{47}$ ), and adequate spectral metrics must be used or implemented to allow the intercomparison of spectra (see, e.g., Gueriau et al. $\left.{ }^{23,45}\right)$.

\section{ALTERABILITY AND LONG-TERM RESILIENCE}

\section{Common Intrinsic Properties}

Constitutive materials of artifacts and ecofacts evolve over long periods of time and also because of specific events in their history. Here, the term alterability does not imply a negative meaning (as the term alteration has in the art history tradition) or a positive meaning. It emphasizes that the consideration and/or description of this transformation is at the heart of the analytical process. These processes do not take place at a regular pace: a short-term event may have a greater impact on alteration than long-term evolving conditions. Dynamic processes can be particularly accelerated when the object is extracted from a relatively stable environment (soil, water). The study of these phenomena is of singular importance in archeology and paleontology and is denominated taphonomy (literally "law of burial"). In a similar way, conservation sciences study the evolution phenomena affecting art and heritage materials, usually considered as "degradation", which denomination also introduces a bias in reference to an idealized original artifact. These transformation processes of materials are studied here both from an applied point of view (e.g., the impact of differential preservation on the archeological record, called "taphonomic bias") and from a fundamental one (understanding of the processes of corrosion in archeological contexts, etc.). Corresponding common intrinsic properties can again be grouped into several main categories:

- Link with contexts: Physico-chemical studies need to take into account cultural and environmental contexts. Knowledge of the successive boundary conditions (redox, temperature, pressure, geochemical composition) is essential for proper interpretation of the analytical results. Conversely, material study can provide information on the successive contexts encountered by an object or series of objects.

- Alteration: The physics and chemistry of alteration on different time scales and its material translation are essential both to qualify the results obtained and to study these behaviors themselves. The very notion of alteration depends on the scale and the observable because, for example, nucleation of dispersed nanocrystals may lead to significant changes in chemical speciation (observable with XAS) but not alter the chemical composition at microscopic scales (observable with $\mu \mathrm{XRF})$.

- Resistance: The external and internal morphologies of an object can resist while its chemistry changes and vice versa. In fact, a two-entry table can be defined, as illustrated, for example, in paleontology: "shape preserved-chemistry preserved" ("exceptional preservation"), "shape preserved-chemistry altered" (e.g., fossilization), "shape altered-chemistry preserved" (e.g., dispersed biomarkers), and "shape alteredchemistry altered" (total loss). Material resilience is where long-term preservation is ensured by self-healing processes under appropriate environmental conditions. 
- Sensitivity: Heritage objects require special conditions of handling because of their mechanical and chemical sensitivity. It is often essential to ensure control of environmental conditions through proper storage, transport, and handling, including during analysis. Irradiation can lead to both material damage and alteration of data (e.g., redox change due to high-flux irradiation), representing a fundamental physical limit for high-dose analyses.

Transformation processes of materials are studied for two main purposes: (a) to collect information on past states recorded in the materiality of objects under study (identifying manufacturing techniques, recognizing wear patterns or the artist's intention, interpreting the morphology of extinct species, etc.) and (b) to understand alteration mechanisms (reconstructing the different steps of alteration, understanding burial environments, informing conservation treatments). Most of the time scales considered in the kinetic evolution of ancient materials are incompatible with experimentation, and we have access only to the present state of the materials, apart from their recent past. It is often just as important to understand the historical trajectory of materials (the succession of physicochemical phenomena linked to their composition and the environment(s) through which they were transformed) as it is to go back over the information relating to a supposedly "original" state. The recovery of static signatures of dynamic processes (e.g., diffusion, reactive transport, chemical reactions, phase transitions, etc.) is the main means of inferring these trajectories, often by comparison with reproduced model systems or modern analogues (e.g., with diffusion profiles in modern materials).

\section{Experimental Modalities}

As alteration generally leads to phase transitions, speciation, and/or redox changes, excitation/emission point spectrometric and structural techniques (e.g., FT-IR, UV/vis PL spectroscopy, XAS, X-ray Raman spectroscopy, XRD, etc.) are essential to study local alteration processes. Beyond point analysis, single-channel images (e.g., tomographic volumes, which are gray-level images characterizing the attenuation of the material in each voxel) already provide facies that are highly characteristic of certain dynamic processes (nucleation and growth, transport, drying, etc.). $\mu \mathrm{CT}$ can be used to determine the $3 \mathrm{D}$ distribution of compounds when the corresponding linear attenuations are sufficiently distinct to be matched to individual compounds. ${ }^{3,48}$ Spectral imaging provides an essential complement by making it possible to collect spectra (or data of higher dimensionality) carrying speciation information in each voxel. A typical example is presented by Gueriau et al. $^{49}$ and Davesne et al., ${ }^{25}$ who used spectral imaging data to assess local redox conditions associated with the fossilization of $\sim 100 \mathrm{Ma}$ fishes from Morocco at different time intervals. The authors identified, on the one hand, iron oxides that formed during decay and, on the other hand, oxidized $\mathrm{Ce}(\mathrm{IV})$ that was incorporated into bone and phosphatized muscles thousands of years later, revealing an early establishment of oxidative conditions around or near the carcasses. Another example comes from the search for metallurgical process markers in corroded archeological metal artifacts, which is essential to better understand the evolution of techniques and material flows in past societies. For instance, Thoury et al. ${ }^{1}$ were able to reconstruct the precise thermal and chemical history of a 6000-year-old amulet from the Mehrgarh site from microstructure analysis and compound identification using spectral imaging of the artifact's entirely corroded $\mathrm{Cu}_{2} \mathrm{O}$ based matrix. Exploitation of known semiconductor emission properties led to the development of high-definition PL imaging modalities that allowed the discovery of a hidden fossilized eutectic pattern (Figure 5). Although the original
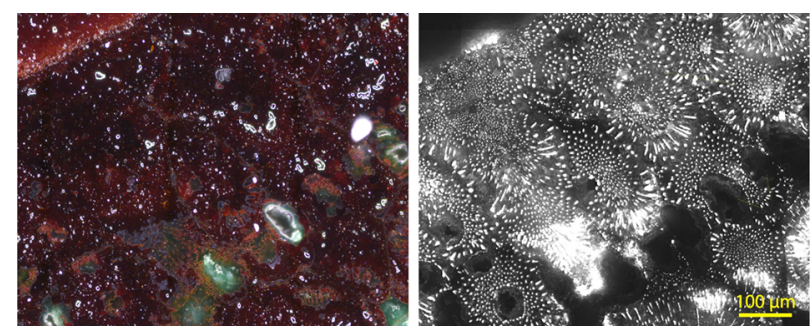

Figure 5. Preservation of a eutectic microstructure over the entire wheel-shaped 6000-year-old Mehrgarh Amulet: (left) dark-field microscopy image of the close-up of a spoke of the amulet showing the ubiquitous presence of the red phase, $\mathrm{Cu}_{2} \mathrm{O}$; (right) PL image of the same area under excitation in the range $420-480 \mathrm{~nm}$ collected in the emission range $850-1020 \mathrm{~nm}$ ( $40 \times$ objective, numerical aperture $0.6)$. Imaging revealed a regular pattern at the micrometer scale corresponding to the preserved eutectic microstructure in the interdendritic spaces despite the extensive corrosion of the object.

chemical contrast between the $\mathrm{Cu}$ and $\mathrm{Cu}_{2} \mathrm{O}$ phases of the eutectic pattern was erased by the slow corrosion of $\mathrm{Cu}$ to $\mathrm{Cu}_{2} \mathrm{O}$ over thousands of years, the original morphology of the eutectic was shown to be still recoverable down to the nanoscale by differential contrast of the trap state emissions.

High photon fluxes can induce the formation of defects or damage. The strategies adopted to minimize radiation-induced side effects include decreasing the flux to an acceptable level in terms of the ratio between the information collected and the risks. ${ }^{45,50-54}$ It is important to minimize the degradation of the original chemical information during the analysis itself. ${ }^{55}$ An example of this risk is the photo-oxidation of $\mathrm{Ce}$ (III) to $\mathrm{Ce}(\mathrm{IV})$ in fossils during analysis of cerium speciation, a frequently used redox proxy of the past environment (Figure 6). The dose provided by collecting entire Ce XAS spectra clearly alters the information about the preserved oxidation state; this could be overcome by reducing Ce spectra to a limited number of excitation energy points in order to extract $[\mathrm{Ce}(\mathrm{IV})] /[\mathrm{Ce}($ tot $)]$ ratios that are unaffected by X-ray irradiation $^{44,45}$ (Figure 3). A practical threshold for this application of the "as low as reasonably achievable" (ALARA) principle, aimed at minimizing the effects of irradiation, ${ }^{55}$ is attained when obtaining (a) an activity image representing the spatial distribution of the property studied and (b) an interpretable representative spectrum for each class, as discussed, for example, in applications of XAS or FT-IR imaging. ${ }^{44,56,57}$

\section{SINGULARITY AND REPRESENTATIVENESS}

\section{Common Intrinsic Properties}

The singularity of ancient systems leads to several issues: the information is very lacunary, especially for the oldest periods; the trajectory of each object is singular for both historical and physicochemical reasons; this trajectory is impossible to simulate experimentally, and given the singularity of the objects, each experiment will itself have a singular and 


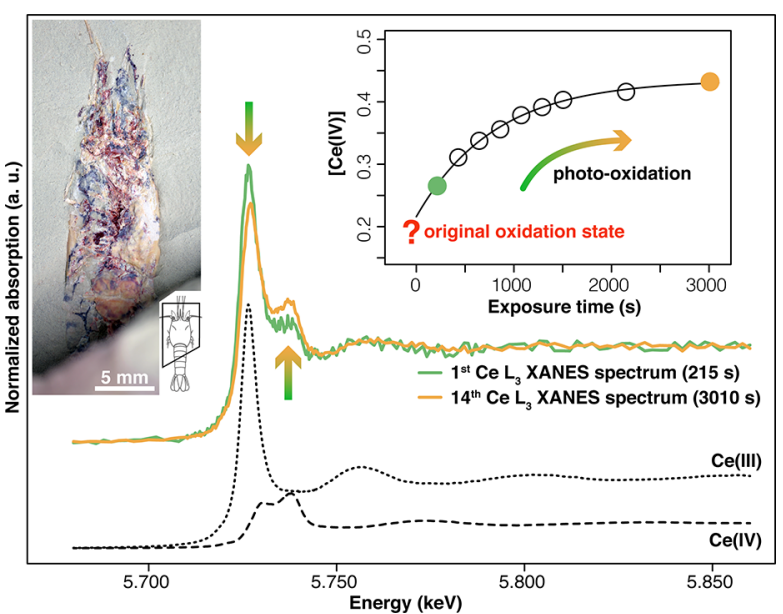

Figure 6. Photo-oxidation kinetics of Ce in apatitic soft tissues of the penaeid shrimp Cretapenaeus berberus from the Jbel oum Tkout

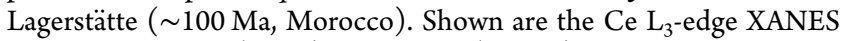
spectra after $215 \mathrm{~s}$ (green) and $3010 \mathrm{~s}$ (orange) of measurements in a cross-section through the abdomen of the specimen pictured in the left inset. The right inset shows the kinetic behavior of $[\mathrm{Ce}(\mathrm{IV})]$ as a function of the accumulation time.

nonreproducible dimension. These lead to several properties of the materials studied:

- Lack of a priori knowledge: the strategies to be adopted cannot be the same as those used in many fields of physics that focus on model materials whose properties can be optimized, at least in part, along the characterization process.

- Nonreproducibility: data on ancient objects are often rare, not only because they may be valuable and because it is often impossible to reanalyze objects at a certain point in time, but also because they provide nonsubstitutable evidence. Noninvasive methods are therefore particularly important.

- Presence of original remains: differential diagenesis (defined as "physical and chemical processes that affect sedimentary materials after deposition and before metamorphism and between deposition and weathering"58) leads to the preservation of specific phases/ compounds while others evolve. Works have reported remains of local traces of "original" materials in a range of ancient systems (e.g., the presence of amplifiable traces of ancient DNA within remineralized bones). These traces are of fundamental interest because they provide direct evidence of the original chemistry. The word "traces" should not be understood solely as a spatial singularity: they may also consist of inclusions located in space or in a diluted form. For ancient systems, their presence is always linked to the chemistry of local microenvironments. ${ }^{59}$

- Lack of ground truth: the data collected are often those that offer the "best possible view". We do not know of a method for generating reference measurements that would validate the whole analytical sequence, even on a small fraction of the objects studied or at a higher cost (in terms of time, budget, access to objects, or access to instruments).

\section{Experimental Modalities}

Beyond what is expected, critical information often comes from what is not previously expected. Many studies therefore start with exploratory analyses free from a series of a priori knowledge, adopting a naturalistic approach to analyze a material "as is". For example, the search for spatial signatures in photoluminescence in an object for which no specific signature is expected is both a bold and low-risk process because luminescence is a "broad" probe by its sensitivity to defects and traces, which are omnipresent in our systems and often strongly correlated with morphological information. The approach is paradigmatically different from that used for purer modern, synthetic materials. A useful concept is provided by the intelligence community: information can result from "known knowns", "known unknowns", "unknown knowns", and finally "unknown unknowns". Each of these four quadrants corresponds to a distinct analytical strategy. The identification of "unknown unknowns" in spectral images prompts the development of holistic and serendipitous approaches, typically in three stages: (i) a "collect it all" image collection strategy with little prerequisite, followed by (ii) a manual search for correlations or unsupervised classification of data, and (iii) a decomposition that can be iterated to verify that all possible factors have been taken into account in the data residues. For the experimenter, and especially on large instruments, it is also necessary to differentiate between rapid evaluation of data during the experiment, which makes it possible to orient the sequence of the analysis being carried out, and a posteriori processing of the data.

The identification and study of weak signals homogeneously distributed in diluted systems allows one to locate diluted outliers and to study the system beyond its average behavior. The aliphatic molecular residues detected in a carboniferous wood fragment were interpreted as pockets of molecular preservation (or at least less alteration) of the original compounds. ${ }^{2}$ The study of weak signals in singular places in relation to a morphology therefore allows the identification of localized outliers that would otherwise go unnoticed with macroscopic data acquisitions. In some cases, investigation of signal deviation from the average behavior was unsuccessful, which in itself can be important information, as in the observed lack of change in calcium speciation in the areas of archeological fish otoliths contacting the sediment. ${ }^{60}$ For example, the regular observation of a very low intensity FT-IR signal in a specific layer of the stratigraphy of a musical instrument was used to validate jointly the existence of this layer and the presence of this specific signature (attributed to an iron-containing clay). ${ }^{61} \mathrm{Li}$ et al. ${ }^{48}$ discovered an unforeseen minor mineral phase in the $3 \mathrm{D} \mu \mathrm{CT}$ image of a heavily corroded copper-based metal slab from the archeological site of Nausharo. This result was obtained by iteratively subtracting the contributions from the previously identified phases from the histogram of the gray values of the image. Subsequent validation of the presence of this phase came from observation of the colocalization of sulfur in energy-dispersive X-ray spectroscopy (EDS) images collected with scanning electron microscopy (SEM) (Figure 7). The discovery of such phases is important to accurately describe the corrosion processes involved and the long-term preservation of artifacts transformed over time.

Additional examples are the discovery of an unexpected lowdensity phase in 3D images of 1.88-Ga-old gunflint microfossils, later attributed to kerogens resulting from diagenesis of 


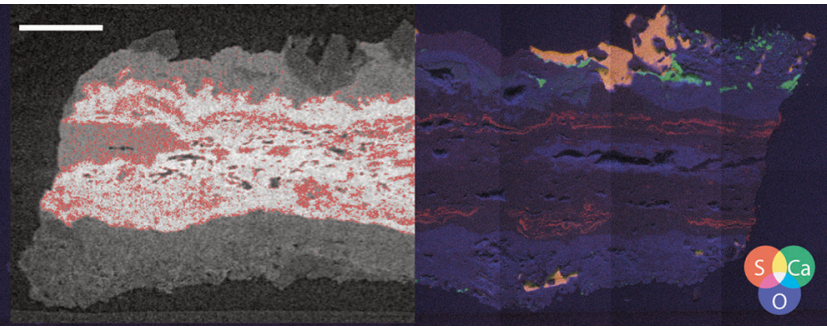

Figure 7. (left) Virtual section in the reconstructed X-ray microtomography volume of a copper-based slab with mineralized textiles at its surface from the archeological site of Nausharo (first half of the third millennium $\mathrm{BC}$ ), showing pixels belonging to a previously unidentified complex mineral phase (in red, linear attenuation ca. 3.0 $\mathrm{cm}^{-1}$ ). Scale bar: $200 \mu \mathrm{m}$. (right) False-color EDS image obtained by SEM on a cross-section subsequently performed on the sample: sulfur (red), calcium (green), oxygen (blue). A correlation is noted between pixels of the compounds identified in red and the presence of sulfur.

the original organic matter, ${ }^{4}$ or the 3D distinction of two levels of preservation of the exoskeleton in a fossil ant preserved in amber. $^{2}$ In the latter, Georgiou et al. ${ }^{2}$ reported the unprecedented use of a hard X-ray probe based on X-ray Raman scattering for imaging in three dimensions the carbon chemistry of an $\sim 53 \mathrm{Ma}$ ant from France (Figure 8 ). Although

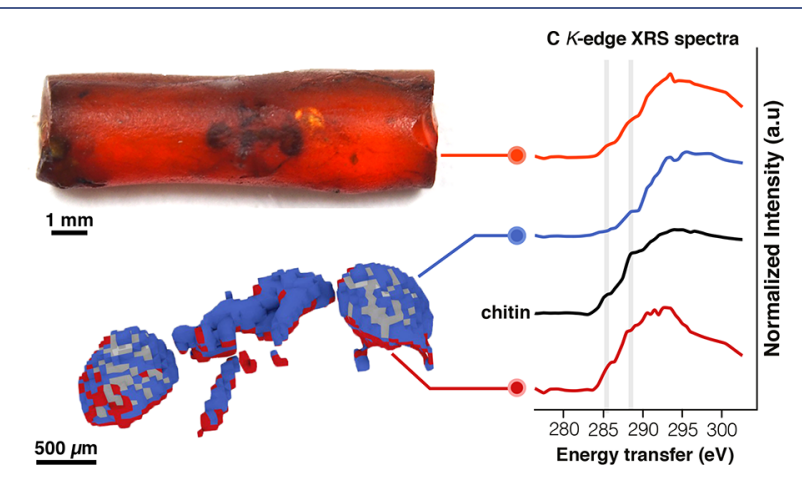

Figure 8. Discrimination of two differently altered chemical compositions in the cuticle of an ant trapped in amber 53 million years ago (Oise, France). 3D carbon speciation, obtained through carbon K-edge X-ray Raman spectroscopy, allowed the ant to be virtually extracted from the amber and revealed the preservation of chitin molecular signatures that were better preserved on its ventral surface (dark red) that had been first in contact with the resin than on its dorsal surface. The vertical gray lines at 285.4 and $288.3 \mathrm{eV}$ are attributed to $1 \mathrm{~s}-\pi^{*}$ transitions from aromatic-olefin carbons and amide groups, respectively.

the resolution obtained is much lower than that of $\mu \mathrm{CT}$, the authors distinguished two degrees of preservation within the ant's exoskeleton, with the surface of the ant that was likely brought into contact with the resin first appearing better chemically preserved than areas covered later after the ant's death.

The need for holistic low a priori approaches explains the development of many modalities of raster scanning of artworks (e.g., using XRF and XRD) or of hyperspectral imaging. This is well-illustrated by the development of XRF mapping for large objects such as fossils: while a common practice was to record only integrated intensities for elements of interest in order to reduce scanning times, ${ }^{24}$ collection of the full XRF spectra in similar objects and their full decomposition allowed the distribution of additional trace elements, such as the taphonomically important rare-earth elements (REEs), to be identified and their concentration to be estimated. ${ }^{23,45}$ It is important to note here that although matrix reabsorption corrections are essential for estimating elemental concentrations, they are not required to study contrasts coming from different phases, as the XRF data can be interpreted as the stochastic result of a photon-matter interaction: the signal variations induced by the composition of the matrix can be as interesting as the elementary contents studied.

\section{CONCLUSION}

Because of their intrinsic properties, the study of ancient material can benefit greatly from new advances at third- and fourth-generation synchrotrons that significantly increase the limits in resolution, flux, and coherence, making hyperspectral imaging a common modus operandi (e.g., SOLEIL, Max IV, ESRF-EBS, Sirius). For example, the PUMA beamline at SOLEIL allows one to go from the macro- to micrometer scale with multimodal detection systems, while the Carnauba beamline, recently developed at Sirius, will reach the nanometer scales in a complementary way, with similar hyperspectral capabilities. The operation of this equipment poses significant computational and mathematical challenges, particularly with regard to the processing of large datasets.

In practice, repeated iterations between the questioning of objects and methodological development can evolve toward promising new research directions. This process can either be initiated from a specific scientific questioning or from a new methodological idea. This feedback between measure and questioning is not only a question of instruments and skills; heritage objects play an essential role in the translation of concepts at the interdisciplinary frontier ${ }^{6,7}$ (Figure 9). We

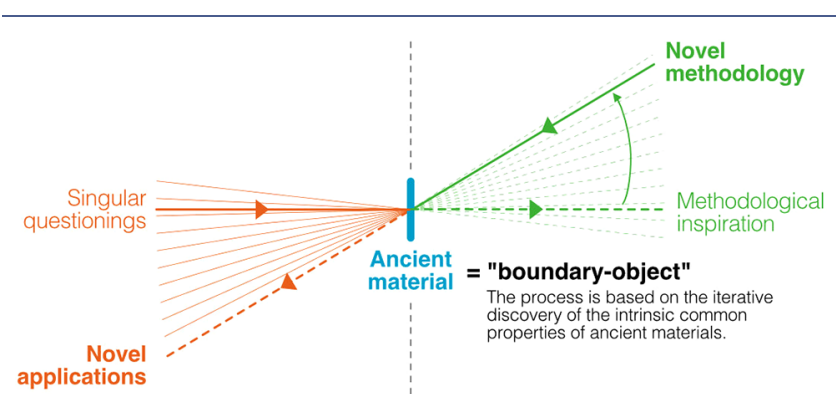

Humanities and environmenta sciences Archaeology, Paleontology, Paleo-environments, Art history \& Conservation sciences

$$
\begin{aligned}
& \text { Natural sciences Chemistry, } \\
& \text { Physics, Statistics, Signal, Optics, } \\
& \text { Instrumentation... }
\end{aligned}
$$

Figure 9. Schematic representation of the progressive development of new applications based on singular questions raised in heritage sciences pointing to the role of ancient material systems as "boundary objects".

believe that the development of interdisciplinary platforms or teams dedicated to ancient and heritage materials that couple fundamental methodological research and application ${ }^{62-64}$ is a favorable factor in encouraging such innovation and that the approach of identifying the intrinsic specificities of the materials studied plays a central role here, even leading to a more precise definition of "ancient material" as a relational concept.

In particular, many of the examples presented are based on a close coupling between chemical and morphological information allowed by new methods of data characterization and 
analysis based on $2 \mathrm{D}$ and $3 \mathrm{D}$ spectral imaging. By responding to a number of specificities of ancient materials, they open up particularly promising methodological approaches. The preeminence of correlations is promising for the use of machine learning techniques. The study of materials for which we have irretrievably lost a part of the information on their formation and evolution and that contain an informative part of vagueness (see Sørensen ${ }^{65}$ and references therein) leads us to accept this missing part as a fundamental contribution to their apprehension and study. In this respect, it is necessary to detach ourselves from overdeterministic or fixist scientific models and to prefer stochastic models that take into account informational uncertainty and the ruptures encountered by systems over time. Apart from this question of displacement with respect to standard concepts and the borderline between nature and culture, an important point is therefore that of the construction of nonlinear or discontinuous models. A target objective could therefore be to construct trajectories of material change over time in a plurality of environmental contexts. One could even think that ancient materials are unique to study these discontinuous transformation processes, with very diverse kinetics, in order to lay the foundations of new epistemological models of materials immersed in time.

\section{AUTHOR INFORMATION}

\section{Corresponding Authors}

Loïc Bertrand - Université Paris-Saclay, ENS Paris-Saclay, CNRS, PPSM, F-91190 Gif-sur-Yvette, France; 이이.org/ 0000-0001-6622-9113; Email: loic.bertrand@ens-parissaclay.fr

Serge Cohen - Université Paris-Saclay, CNRS, ministère de la culture, UVSQ, MNHN, IPANEMA, F-91192 Saint-Aubin, France; 10 orcid.org/0000-0003-2435-2417; Email: serge.cohen@synchrotron-soleil.fr

\section{Authors}

Mathieu Thoury - Université Paris-Saclay, CNRS, ministère de la culture, UVSQ MNHN, IPANEMA, F-91192 SaintAubin, France; (1) orcid.org/0000-0002-8641-3791

Pierre Gueriau - Institute of Earth Sciences, University of Lausanne, CH-1015 Lausanne, Switzerland; 이이.org/ 0000-0002-7529-3456

Étienne Anheim - Centre de recherches historiques, EHESS, CNRS, F-75006 Paris, France; 이이이.org/0000-00026888-4688

Complete contact information is available at:

https://pubs.acs.org/10.1021/acs.accounts.1c00063

\section{Notes}

The authors declare no competing financial interest.

\section{Biographies}

Loïc Bertrand is a physical chemist at the PPSM Laboratory of Chemistry of the ENS Paris-Saclay. After graduating from the École Polytechnique and the École des mines de Paris, he obtained his Ph.D. from the Université Pierre-et-Marie-Curie (Sorbonne Université), working at the École Normale Supérieure (Paris) and the C2RMF. He worked successively at the Department of Biochemistry of the University of Cambridge, the Laboratoire de physique des solides in Orsay, and the SOLEIL synchrotron, where he founded the European IPANEMA laboratory on ancient materials, which he headed from 2009 to 2019 before joining Universite Paris-Saclay.
Mathieu Thoury was trained as an optical engineer. He has devoted his research to the study of cultural heritage materials and paleontology for the past 10 years. Between 2002 and 2006, he did his thesis at the INSP and the C2RMF (Paris) and, as part of a postdoctoral fellowship, joined the scientific department of the National Gallery of Art in Washington, D.C., for 4 years. He then worked at the Centre de recherche sur la conservation des collections (Paris) between 2010 and 2011. Since 2011, he has been part of IPANEMA.

Pierre Gueriau is a paleontologist whose research particularly focuses on deciphering fossilization mechanisms through the use and development of advanced spectro-imaging techniques. He completed his Ph.D. at the Muséum national d'Histoire naturelle (Paris) and then worked successively as a postdoctoral researcher at the SOLEIL synchrotron, IPANEMA, and the University of Lausanne.

Étienne Anheim was trained at the École normale supérieure de Fontenay/Saint-Cloud and the École française de Rome and is Professor in Medieval History at the École des hautes études en sciences sociales (Paris). He was vice-president of the Fondation des sciences du patrimoine (2013-2021). He is a member of the scientific board of the Louvre Museum, and Head of the EHESS University Press. He was Editor-in-Chief of Annales. Histoire, Sciences Sociales from 2011 to 2018.

Serge Cohen was initially trained in mathematics and physics and has been involved in research activities on ancient materials since 2007, with a first phase of prospective studies that enabled him to condense the determining characteristics common to ancient materials from the point of view of the analysis of the corresponding data. His research focuses on developing mathematical methods for the analysis of spectro-microscopic images of complex heterogeneous materials.

\section{ACKNOWLEDGMENTS}

We thank Barbara Berrie (National Gallery of Art, Washington, D.C., U.S.) and Agnès Desolneux (Centre Borelli, ENS ParisSaclay, CNRS) for their careful rereading of our manuscript. The authors are particularly grateful to the large number of colleagues with whom we have discussed these aspects over many years of common work and interaction. Our very special thanks go to Marie-Angélique Languille (today at the Centre de Recherche sur la Conservation des Collections, Paris) and Sophie David (PPSM). We thank all of our coauthors from the papers discussed and the many colleagues with whom we have discussed these ideas, including Demetrios Anglos, Julie Arslanoglu, Bernadette Bensaude-Vincent, Uwe Bergmann, Barbara Berrie, Catherine Brechignac, Gilles Celeux, Antoine Chambaz, Pierre Chastang, Cynthia Colmellere, Marie Cornu, Jean-Paul Demoule, Agnès Desolneux, Jean-Philippe Échard, Douglas Galante, Pierre Galtier, Claire Gervais, Denis Gratias, Agnès Grimaud, Charlotte Guichard, Ineke Joosten, Katrien Keune, Andrew King, Bertrand Lavédrine, Pierre Laszlo, Erwan Le Pennec, Pierre Levitz, Alain Lusson, Lara Maldanis, Pascal Massard, Cristian Mocuta, Lionel Moisan, Emmanuel (Manolis) Pantos, André Rassat, Matthieu Réfrégiers, Luc Robbiola, Laurent Romary, Isabelle Rouget, Jean-Pascal Rueff, Solenn Réguer, Clément Sanchez, Sebastian Schoeder, Marika Spring, Maartje Stols-Witlox, Matija Strlic, Caroline Tokarski, Edward Vicenzi, Laurence de Viguerie, Kees van der Beek, Robert van Langh, Philippe Walter, Sam Webb, and many friends, students, and colleagues. L.B. acknowledges the support of the Fondation des Treilles and its wonderful team for the organization of two seminars (in 2013 and 2014) that enabled 
the scope of this research program to be critically defined. The construction of the IPANEMA laboratory was funded by a CPER grant from the French Ministère de la recherche, de l'enseignement supérieur et de l'innovation and Région Île-deFrance.

\section{REFERENCES}

(1) Thoury, M.; Mille, B.; Séverin-Fabiani, T.; Robbiola, L.; Réfrégiers, M.; Jarrige, J.-F.; Bertrand, L. High spatial dynamicsphotoluminescence imaging reveals the metallurgy of the earliest lost wax-cast object. Nat. Commun. 2016, 7, 13356.

(2) Georgiou, R.; Gueriau, P.; Sahle, C.; Bernard, S.; Mirone, A.; Garrouste, R.; Bergmann, U.; Rueff, J.-P.; Bertrand, L. Carbon speciation in organic fossils using $2 \mathrm{D}$ to $3 \mathrm{D}$ X-ray Raman multispectral imaging. Sci. Adv. 2019, 5, No. eaaw5019.

(3) Reynaud, C.; Thoury, M.; Dazzi, A.; Latour, G.; Scheel, M.; Li, J.; Thomas, A.; Moulherat, C.; Didier, A.; Bertrand, L. In-place molecular preservation of cellulose in 5,000-year-old archaeological textiles. Proc. Natl. Acad. Sci. U. S. A. 2020, 117, 19670-19676.

(4) Maldanis, L.; Hickman-Lewis, K.; Verezhak, M.; Gueriau, P.; Guizar-Sicairos, M.; Jaqueto, P.; Trindade, R.; Rossi, A. L.; Berenguer, F.; Westall, F.; Bertrand, L.; Galante, D. Nanoscale 3D quantitative imaging of $1.88 \mathrm{Ga}$ Gunflint microfossils reveals novel insights into taphonomic and biogenic characters. Sci. Rep. 2020, 10, 8163.

(5) Spoto, G.; Torrisi, A.; Contino, A. Probing archaeological and artistic solid materials by spatially resolved analytical techniques. Chem. Soc. Rev. 2000, 29, 429-439.

(6) Anheim, E.; Thoury, M.; Bertrand, L. Micro-imagerie de matériaux anciens complexes (I). Rev. Synth. 2015, 136, 329-354.

(7) Bertrand, L.; Thoury, M.; Anheim, E. Ancient materials specificities for their synchrotron examination and insights into their epistemological implications. J. Cult. Heritage 2013, 14, 277289.

(8) Trentelman, K. Analyzing the Heterogeneous Hierarchy of Cultural Heritage Materials: Analytical Imaging. Annu. Rev. Anal. Chem. 2017, 10, 247-270.

(9) Brissaud, I.; Wang, J. X.; Chevallier, P. Synchrotron radiation induced X-ray fluorescence at LURE. J. Radioanal. Nucl. Chem. 1989, 131, 399-413.

(10) Harbottle, G.; Gordon, B. M.; Jones, K. W. Use of synchrotron radiation in archaeometry. Nucl. Instrum. Methods Phys. Res., Sect. B 1986, 14, 116-122.

(11) Bergmann, U.; Bertrand, L.; Edwards, N. P.; Manning, P. L.; Wogelius, R. A. Chemical Mapping of Ancient Artifacts and Fossils with X-ray Spectroscopy. In Synchrotron Light Sources and FreeElectron Lasers: Accelerator Physics, Instrumentation and Science Applications; Jaeschke, E., Khan, S., Schneider, J. R., Hastings, J. B., Eds.; Springer: Cham, Switzerland, 2019.

(12) Gueriau, P.; Bernard, S.; Bertrand, L. Advanced synchrotron characterization of paleontological specimens. Elements 2016, 12, 4550.

(13) Bertrand, L.; Bernard, S.; Marone, F.; Thoury, M.; Reiche, I.; Gourrier, A.; Sciau, P.; Bergmann, U. Emerging approaches in synchrotron studies of materials from cultural and natural history collections. Top. Curr. Chem. 2016, 374, 7.

(14) Bertrand, L. Methodological Developments and Support for Synchrotron Investigation in Cultural Heritage and Archaeology. In Trends of Synchrotron Radiation Applications in Cultural Heritage, Forensics and Materials Science; IAEA TecDoc 1803; International Atomic Energy Agency: Vienna, Austria, 2016; pp 48-59.

(15) Bertrand, L.; Robinet, L.; Thoury, M.; Janssens, K.; Cohen, S. X.; Schöder, S. Cultural heritage and archaeology materials studied by synchrotron spectroscopy and imaging. Appl. Phys. A: Mater. Sci. Process. 2012, 106, 377-396.

(16) Bertrand, L.; Cotte, M.; Stampanoni, M.; Thoury, M.; Marone, F.; Schöder, S. Development and trends in synchrotron studies of ancient and historical materials. Phys. Rep. 2012, 519, 51-96.
(17) Bertrand, L. Synchrotron imaging for archaeology, art history, conservation and paleontology. In Physical Techniques in the Study of Art, Archaeology and Cultural Heritage; Creagh, D. C., Bradley, D. A., Eds.; Elsevier Science, 2007; Vol. 2; pp 97-114.

(18) Janssens, K.; Alfeld, M.; Van der Snickt, G.; De Nolf, W.; Vanmeert, F.; Radepont, M.; Monico, L.; Dik, J.; Cotte, M.; Falkenberg, G.; Miliani, C.; Brunetti, B. G. The Use of Synchrotron Radiation for the Characterization of Artists' Pigments and Paintings. Annu. Rev. Anal. Chem. 2013, 6, 399-425.

(19) Cotte, M.; Susini, J. Advances and Perspectives of SynchrotronBased Techniques for Cultural Heritage. In Proceedings of the International School of Physics Enrico Fermi, 194th Workshop on Future Research Infrastructures-Challenges and Opportunities, Varenna, Italy, July 9-11, 2015; IOP Press, 2016; pp 119-129.

(20) Alfeld, M.; Siddons, D. P.; Janssens, K.; Dik, J.; Woll, A. R.; Kirkham, R.; van de Wetering, E. Visualizing the 17th century underpainting in Portrait of an Old Man by Rembrandt van Rijn using synchrotron-based scanning macro-XRF. Appl. Phys. A: Mater. Sci. Process. 2013, 111, 157-164.

(21) Bull, D.; Krekeler, A.; Alfeld, M.; Dik, J.; Janssens, K. An Intrusive Portrait by Goya. Burlington Mag. 2011, CLII, 668-673.

(22) Manning, P. L.; Edwards, N. P.; Wogelius, R. A.; Bergmann, U.; Barden, H. E.; Larson, P. L.; Schwarz-Wings, D.; Egerton, V. M.; Sokaras, D.; Mori, R. A.; Sellers, W. I. Synchrotron-based chemical imaging reveals plumage patterns in a 150 million year old early bird. J. Anal. At. Spectrom. 2013, 28, 1024-1030.

(23) Gueriau, P.; Mocuta, C.; Dutheil, D. B.; Cohen, S. X.; Thiaudière, D.; The OT1 Consortium; Charbonnier, S.; Clément, G.; Bertrand, L. Trace elemental imaging of rare earth elements discriminates tissues at microscale in flat fossils. PLoS One 2014, 9, No. e86946.

(24) Edwards, N. P.; Wogelius, R. A.; Bergmann, U.; Larson, P.; Sellers, W.; Manning, P. Mapping prehistoric ghosts in the synchrotron. Appl. Phys. A: Mater. Sci. Process. 2013, 111, 147-155.

(25) Davesne, D.; Gueriau, P.; Dutheil, D. B.; Bertrand, L. Exceptional preservation of a Cretaceous intestine provides a glimpse of the early ecological diversity of spiny-rayed fishes (Acanthomorpha, Teleostei). Sci. Rep. 2018, 8, 8509.

(26) Gueriau, P.; Lamsdell, J.; Wogelius, R.; Manning, P.; Egerton, V.; Bergmann, U.; Bertrand, L.; Denayer, J. A new Devonian euthycarcinoid reveals the use of different respiratory strategies during the marine-to-terrestrial transition in the myriapod lineage. $R$. Soc. Open Sci. 2020, 7, 201037.

(27) Cotte, M.; Susini, J.; Dik, J.; Janssens, K. Synchrotron-based Xray absorption spectroscopy for art conservation: looking back and looking forward. Acc. Chem. Res. 2010, 43, 705-714.

(28) Leon, Y.; Dillmann, P.; Neff, D.; Schlegel, M. L.; Foy, E.; Dynes, J. J. Interfacial layers at a nanometre scale on iron corroded in carbonated anoxic environments. RSC Adv. 2017, 7, 20101-20115.

(29) Rouchon, V.; Bernard, S. Mapping iron gall ink penetration within paper fibres using scanning transmission X-ray microscopy. J. Anal. At. Spectrom. 2015, 30, 635-641.

(30) Cosmidis, J.; Benzerara, K.; Gheerbrant, E.; Esteve, I.; Bouya, B.; Amaghzaz, M. Nanometer-scale characterization of exceptionally preserved bacterial fossils in Paleocene phosphorites from Ouled Abdoun (Morocco). Geobiol 2013, 11, 139-153.

(31) Gueriau, P.; Rueff, J.-P.; Bernard, S.; Kaddissy, J.; Goler, S.; Sahle, C. J.; Sokaras, D.; Wogelius, R. A.; Manning, P. L.; Bergmann, U.; Bertrand, L. Noninvasive synchrotron-based X-Ray Raman scattering discriminates carbonaceous compounds in ancient and historical materials. Anal. Chem. 2017, 89, 10819-10826.

(32) Sanchez, S.; Tafforeau, P.; Clack, J. A.; Ahlberg, P. E. Life history of the stem tetrapod Acanthostega revealed by synchrotron microtomography. Nature 2016, 537, 408-411.

(33) Tafforeau, P.; Boistel, R.; Boller, E.; Bravin, A.; Brunet, M.; Chaimanee, Y.; Cloetens, P.; Feist, M.; Hoszowska, J.; Jaeger, J.-J.; Kay, R. F.; Lazzari, V.; Marivaux, L.; Nel, A.; Nemoz, C.; Thibault, X.; Vignaud, P.; Zabler, S. Applications of X-ray synchrotron micro- 
tomography for non-destructive 3D studies of paleontological specimens. Appl. Phys. A: Mater. Sci. Process. 2006, 83, 195-202.

(34) Tafforeau, P.; Zermeno, J. P.; Smith, T. M. Tracking cellularlevel enamel growth and structure in $4 \mathrm{D}$ with synchrotron imaging. $J$. Human Evol. 2012, 62, 424-428.

(35) Tafforeau, P.; Bentaleb, I.; Jaeger, J.-J.; Martin, C. Nature of laminations and mineralization in rhinoceros enamel using histology and X-ray synchrotron microtomography: Potential implications for palaeoenvironmental isotopic studies. Palaeogeogr., Palaeoclimatol, Palaeoecol. 2007, 246, 206-227.

(36) Friis, E. M.; Crane, P. R.; Pedersen, K. R.; Stampanoni, M.; Marone, F. Exceptional preservation of tiny embryos documents seed dormancy in early angiosperms. Nature 2015, 528, 551-555.

(37) Cotte, M.; Dumas, P.; Taniguchi, Y.; Checroun, É.; Walter, P.; Susini, J. Recent applications and current trends in Cultural Heritage Science using synchrotron-based Fourier transform infrared microspectroscopy. C. R. Phys. 2009, 10, 590-600.

(38) Bertrand, L.; Doucet, J.; Dumas, P.; Simionovici, A.; Tsoucaris, G.; Walter, P. Microbeam synchrotron imaging of hairs from Ancient Egyptian mummies. J. Synchrotron Radiat. 2003, 10, 387-392.

(39) Thoury, M.; Echard, J.-P.; Réfrégiers, M.; Berrie, B.; Nevin, A.; Jamme, F.; Bertrand, L. Synchrotron UV-visible multispectral luminescence micro-imaging of historical samples. Anal. Chem. 2011, 83, 1737-1745.

(40) Hageraats, S.; Keune, K.; Réfrégiers, M.; van Loon, A.; Berrie, B.; Thoury, M. Synchrotron Deep-UV Photoluminescence Imaging for the Submicrometer Analysis of Chemically Altered Zinc White Oil Paints. Anal. Chem. 2019, 91, 14887-14895.

(41) Torquato, S. Random Heterogenous Materials; Springer, 2001.

(42) Johnson, D. H.; Johnson, C. R., Jr.; Erdmann, R. G. Weave analysis of paintings on canvas from radiographs. Signal Process. 2013, 93, 527-540.

(43) Texture is used according to the mathematical definition and not the one used to describe materials corresponding to "preferential orientation".

(44) Cohen, S. X.; Webb, S. M.; Gueriau, P.; Curis, E.; Bertrand, L. Robust framework and software implementation for fast speciation mapping. J. Synchrotron Radiat. 2020, 27, 1049-1058.

(45) Gueriau, P.; Mocuta, C.; Bertrand, L. Cerium anomaly at microscale in fossils. Anal. Chem. 2015, 87, 8827-8836.

(46) Bertrand, L.; Robinet, L.; Cohen, S. X.; Sandt, C.; Le Hô, A.-S.; Soulier, B.; Lattuati-Derieux, A.; Échard, J.-P. Identification of the finishing technique of an early eighteenth century musical instrument using FTIR spectromicroscopy. Anal. Bioanal. Chem. 2011, 399, $3025-3032$.

(47) Bertrand, L.; Réfrégiers, M.; Berrie, B.; Échard, J.-P.; Thoury, M. A multiscalar photoluminescence approach to discriminate among semiconducting historical zinc white pigments. Analyst 2013, 138, 4463-4469.

(48) Li, J.; Gueriau, P.; Bellato, M.; King, A.; Robbiola, L.; Thoury, M.; Baillon, M.; Fossé, C.; Cohen, S. X.; Moulherat, C.; Thomas, A.; Galtier, P.; Bertrand, L. Synchrotron-based phase mapping in corroded metals: insights from early copper-base artefacts. Anal. Chem. 2019, 91, 1815-1825.

(49) Gueriau, P.; Bernard, S.; Farges, F.; Mocuta, C.; Dutheil, D. B.; Adatte, T.; Bomou, B.; Godet, M.; Thiaudière, D.; Charbonnier, S.; Bertrand, L. Oxidative conditions can lead to exceptional preservation through phosphatization. Geology 2020, 48, 1164-1168.

(50) Moini, M.; Rollman, C. M.; Bertrand, L. Assessing the impact of synchrotron x-ray irradiation on proteinaceous specimens at macro and molecular levels. Anal. Chem. 2014, 86, 9417-9422.

(51) Gervais, C.; Languille, M.-A.; Reguer, S.; Gillet, M.; Vicenzi, E. P.; Chagnot, S.; Baudelet, F.; Bertrand, L. "Live" Prussian blue fading by time-resolved X-ray absorption spectroscopy. Appl. Phys. A: Mater. Sci. Process. 2013, 111, 15-22.

(52) Gervais, C.; Languille, M.-A.; Reguer, S.; Gillet, M.; Pelletier, S.; Garnier, C.; Vicenzi, E. P.; Bertrand, L. Why Does Prussian Blue Fade? Understanding the Role(s) of the Substrate. J. Anal. At. Spectrom. 2013, 28, 1600-1609.
(53) Immel, A.; Le Cabec, A.; Bonazzi, M.; Herbig, A.; Temming, H.; Schuenemann, V. J.; Bos, K. I.; Langbein, F.; Harvati, K.; Bridault, A.; Pion, G.; Julien, M.-A.; Krotova, O.; Conard, N. J.; Muenzel, S. C.; Drucker, D. G.; Viola, B.; Hublin, J.-J.; Tafforeau, P.; Krause, J. Effect of X-ray irradiation on ancient DNA in sub-fossil bones - Guidelines for safe X-ray imaging. Sci. Rep. 2016, 6, 32969.

(54) Monico, L.; Cotte, M.; Vanmeert, F.; Amidani, L.; Janssens, K.; Nuyts, G.; Garrevoet, J.; Falkenberg, G.; Glatzel, P.; Romani, A.; Miliani, C. Damages induced by synchrotron radiation-based X-ray microanalysis in chrome yellow paints and related Cr-compounds: assessment, quantification and mitigation strategies. Anal. Chem. 2020, 92, 14164-14173.

(55) Bertrand, L.; Schöeder, S.; Anglos, D.; Breese, M. B. H.; Janssens, K.; Moini, M.; Simon, A. Mitigation strategies for radiation damage in the analysis of ancient materials. TrAC, Trends Anal. Chem. 2015, 66, 128-145.

(56) Cohen, S. X.; Le Pennec, E. Partition-based conditional density estimation. ESAIM-Prob. Stat. 2013, 17, 672-697.

(57) Cohen, S. X.; Le Pennec, E. Unsupervised Segmentation of Spectral Images with a Spatialized Gaussian Mixture Model and Model Selection. Oil Gas Sci. Technol. 2014, 69, 245-259.

(58) Milliken, K. L. Treatise on Geochemistry; Pergamon: Oxford, U.K., 2003.

(59) Bernard, S.; Papineau, D. Graphitic carbons and biosignatures. Elements 2014, 10, 435-440.

(60) Cook, P. K.; Dufour, É.; Languille, M.-A.; Mocuta, C.; Réguer, S.; Bertrand, L. Strontium speciation in archaeological otoliths. J. Anal. At. Spectrom. 2016, 31, 700-711.

(61) Échard, J.-P.; Cotte, M.; Dooryhée, É.; Bertrand, L. Insights into the varnishes of historical musical instruments using synchrotron micro-analytical methods. Appl. Phys. A: Mater. Sci. Process. 2008, 92, $77-81$.

(62) Bertrand, L.; Languille, M.-A.; Cohen, S. X.; Robinet, L.; Gervais, C.; Leroy, S.; Bernard, D.; Le Pennec, E.; Josse, W.; Doucet, J.; Schöder, S. European research platform IPANEMA at the SOLEIL synchrotron for ancient and historical materials. J. Synchrotron Radiat. 2011, 18, 765-772.

(63) Cotte, M.; Pouyet, E.; Salome, M.; Rivard, C.; De Nolf, W.; Castillo-Michel, H.; Fabris, T.; Monico, L.; Janssens, K.; Wang, T.; Sciau, P.; Verger, L.; Cormier, L.; Dargaud, O.; Brun, E.; Bugnazet, D.; Fayard, B.; Hesse, B.; Pradas del Real, A. E.; Veronesi, G.; Langlois, J.; Balcar, N.; Vandenberghe, Y.; Sole, V. A.; Kieffer, J.; Barrett, R.; Cohen, C.; Cornu, C.; Baker, R.; Gagliardini, E.; Papillon, E.; Susini, J. The ID21 X-ray and infrared microscopy beamline at the ESRF: status and recent applications to artistic materials. J. Anal. At. Spectrom. 2017, 32, 477-493.

(64) Prado, G.; Arthuzzi, J. C. L.; Osés, G. L.; Callefo, F.; Maldanis, L.; Sucerquia, P.; Becker-Kerber, B.; Romero, G. R.; Quiroz-Valle, F. R.; Galante, D. Synchrotron radiation in palaeontological investigations: Examples from Brazilian fossils and its potential to South American palaeontology. J. South Am. Earth Sci. 2021, 108, 102973.

(65) Sørensen, T. F. In praise of vagueness: uncertainty, ambiguity and archaeological methodology. J. Archaeol. Method Theory 2016, 23, $741-763$. 